\title{
CHARACTERISTICS OF THE HEALTHY HOUSE AND THEIR INTERRELATIONSHIPS
}

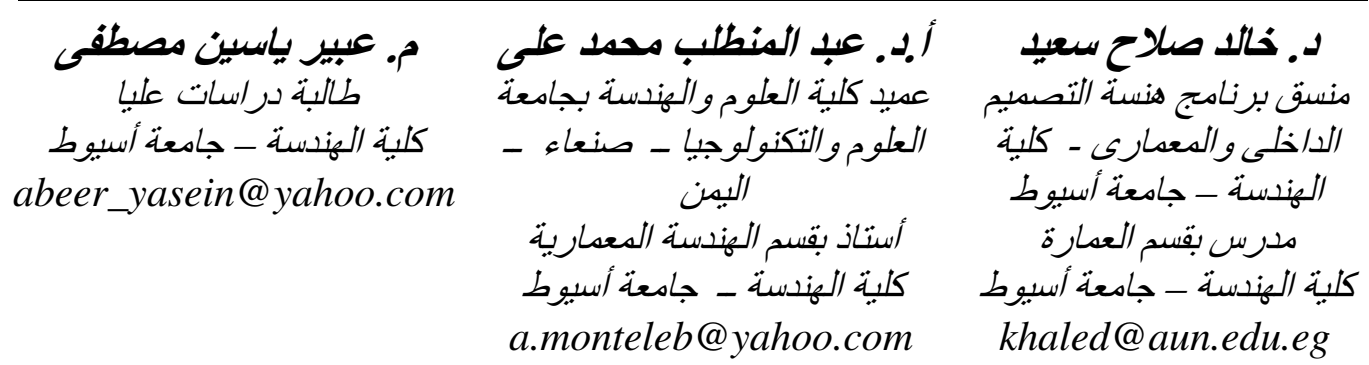

(Received November 14, 2009 Accepted December 7, 2009).

A human health is one of the most important points of concern for States and governments in general. In addition to strategies for prevention of diseases, countries spend vast sums to maintain the health of their individuals. These strategies include the protection of the environments in which human practice different life activities. If the proportion of time spent within the house about $50 \%$ or more, it is normal to have a significant impact on the health of human body, consequently, the residential environment plays an important role in the achievement of health for their users.

Researches and studies, including both architectural or health studies has varied in perceptions and visions of the healthy house, but these studies did not clearly specify the different characteristics of healthy house that must be taken into consideration during the architectural design process in order to produce houses where there are health conditions makes it a healthy house. So, the main aim of this paper is to induct and classify health characteristics that should be in a healthy house and analyzing its interrelationships.

To achieve the main aim of the research, the study uses descriptive, analytical and deductive methodologies to conclude and classify characteristics of healthy houses. The research studies at first the different definitions and concepts of health and its relationship with house. The second part is studying the interrelationship between design considerations on one hand and health on the other hand. Then the paper studies the principles of healthy housing from different views to conclude a set of characteristics for healthy house.

Finally, the paper presents the most important results of the study and discussion for the results. Then the paper presents some recommendations associated with the research results. 


\section{خصائص المسكن الصحى والعلاقات المتبادلة بينها}

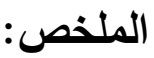

تؤدى البيئة السكنية دوراً هاما فى تحقيق الصحة لمستخدميها، إذ تمثل نسبة ما يقضيه الإنسان من وقته داخل المسكن ما يقارب 50\% أو أكثر ، لذا فإنه من الطبيحى أن يكون للمسكن تأثير كبير على لئه

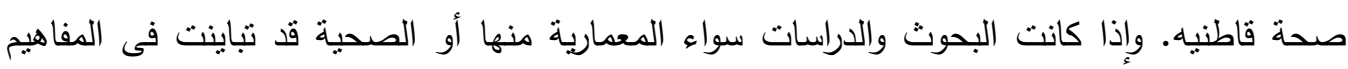

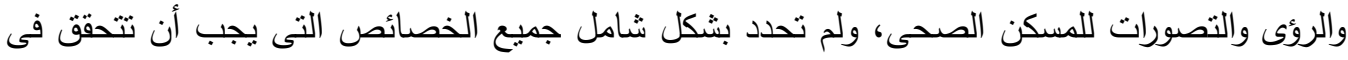

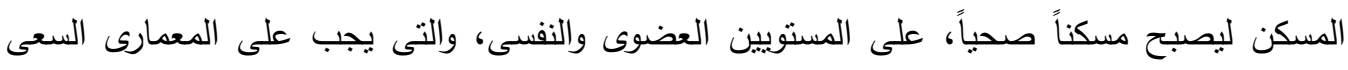
لتحقيقها أثناء العملية التصميمية حتى ينتج مسكناً تتوافر فيه الشروط الصحية التى تجعل منه وله مسكناً صحياً، فإن هذا البحث يهدف إلى إستخلاص وتصنيف الخصائص الصحية للمسكن والملامح العامة للعلاقات المتبادلة بين هذه الخصائص وبعضئها البعض. لهان.

ولتحقيق أهداف البحث فأن الدراسة نستخدم المنهج الوصفى والتحليلى والإسنتباطى للخلوص إلى مجموعة من الخصائص للمسكن الصحى وتصنيفها ودراسة وتحليل العلاقات المتبادلة فيما بينها. وتثتمل الدراسات فى هذه الورقة البحثية على دراسة التعاريف والمفاهيم المختلفة للصحة وعلاقتها

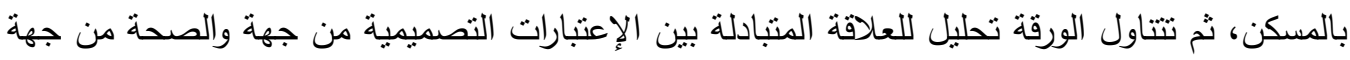
أخرى، ثم دراسة مبادىء وخصائص المسكن الصحى من وجهات نظر متعددة خلوصاً إلى كافة الخصائص الصحية للمسكن وتصنيفها ودراسة العلاقات المتبادلة فيما بينها. ويختتم البحث بأهم نتائج الدراسة ومناقتشة للنتائج مع بعض التوصيات المرتبطة بنتائج البحث من جهة وبالجهات ذات الصلة بموضوع البحث من جهة أخرى.

\section{1- مقدمة (المشكلة والأهداف والمنهجية):}

تمثل صحة الإنسان قضية من أهم القضايا التى تثغل الدول والحكومات بصفة عامة، وتتفق الدول

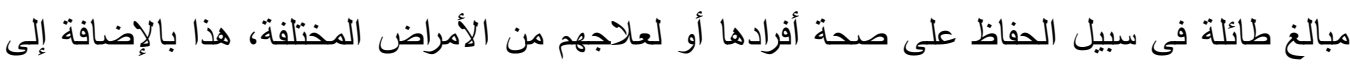

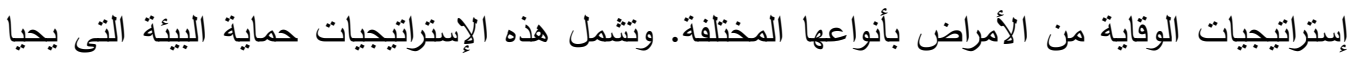

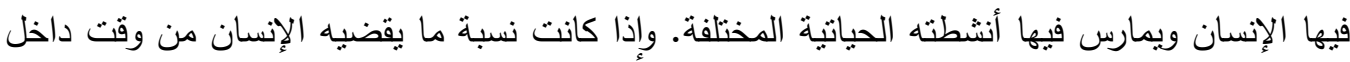

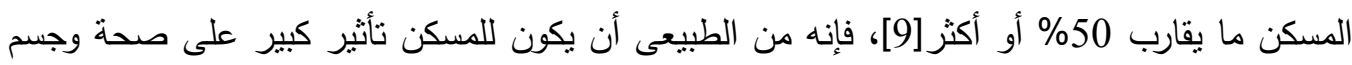

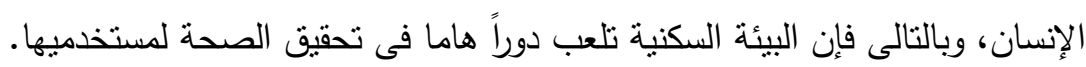

ولهذا فقد إتجهت العديد من البحوث والدراسـات نحو دراسة بعض الجوانب المرتبطة بالمسكن

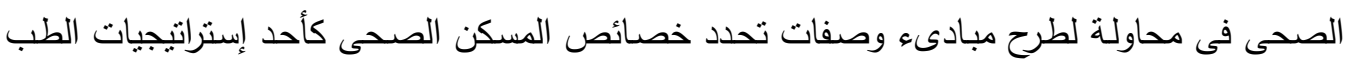


الوقائى من منظور طبى دون التطرق إلى دور التصميم المعمارى فـى تحقيق مسكن صحى بشكل مباشر •

\section{1-1 مشكلة البحث:}

إذا كان نوفير بيئة صحية يعيش فيها الإنسان من مهام مجموعة من الثركاء يمثل المعمارى أحدهم، فهو المسؤول عن تصميم وتشييد مختلف البيئات التى يمارس الإنسان فيها أنشطته الحياتية

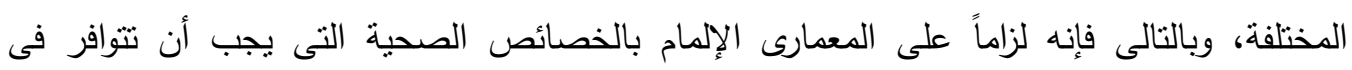

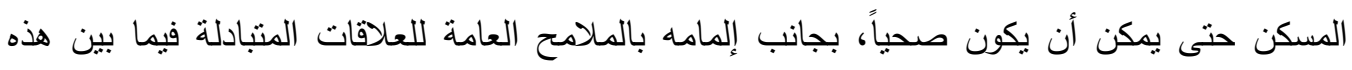

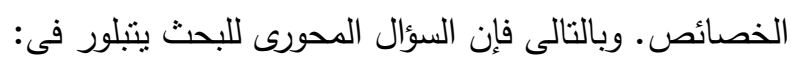

ماهى خصائص المسكن الصحى، وماهى العلاقات المتبادلة فيما بينها؟ وللإجابة على هذا السؤال يجب الإجابة أولاً على بعض التساؤلات الثانوية التى يمكن أن تقود إلى لى لهائ إجابة للسؤال الرئيسى للبحث، وهذه التساؤلات هى:

ماهو مفهوم الصحة، وماهى علاقة الصحة بالمسكن بشكل عام؟ وهل هناك علاقة بين الإعتبارات التصميمية بشكل عام وصحة شاغلى المسكن؟ وماذا

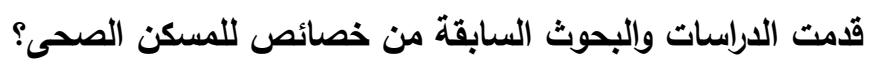

2-1 2 - 2 الدراسات السابقة:

هناك العديد من الدراسات التي نتاولت جوانب من مشكلة البحث أهمها دراسة لمراكز التحكم

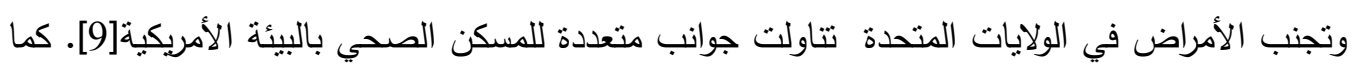
اهتمت دراسات الجمعية الأمريكية لمهندسي التكييف والتدفئة ASHRAE* بتقييم جودة الهواء الهواء الداخلي بالمباني وذللك في الإصدار الخاص بجودة الهواء الداخلي (IAQ) ** والذي بسمي Standard 62-2001 [12]. وتتاولت دراسات منظمة الصحة العالمية وجمعية أمراض الرئة الأمريكية

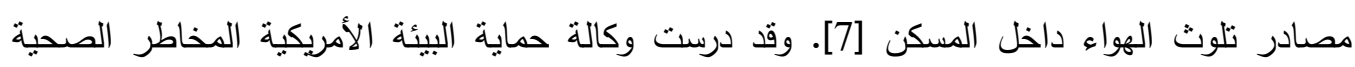
الناجمة عن الملوثات الداخلية للمسكن[11]. بالإضافة إلى ذلك توجد بعض التص الدراسات التى نتاولت

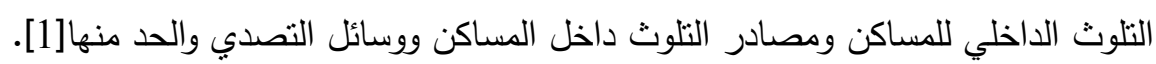
كما تتاولت بعض الدراسات أيضاً الصحة النفسية للإنسان وعلاقتها بسلوك الإنسان داخل والهن

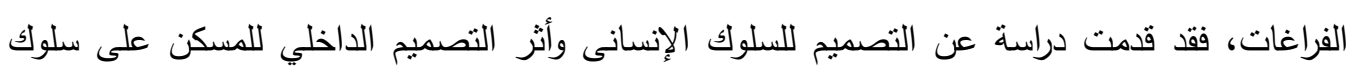

\footnotetext{
* American Society of Heating, Refrigerating and Air-Conditioning

** Indoor Air Quality
} 


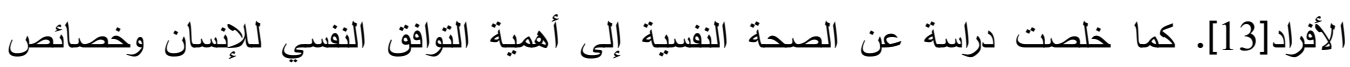

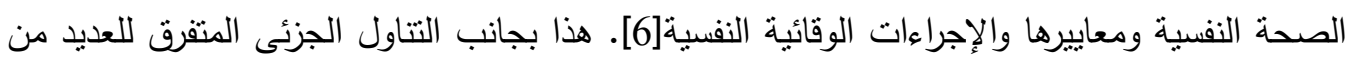
جزئيات المشكلة.

ومن خلال هذه الدراسات السابقة التى أتيحت لدى الباحثين فقد وُجدِ أنها قد تشاركت فى نتاول

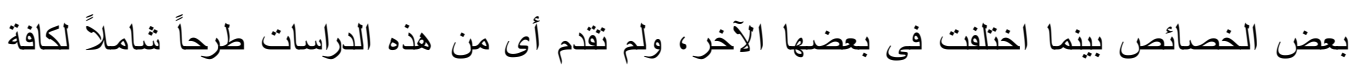

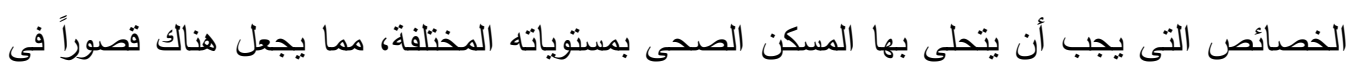

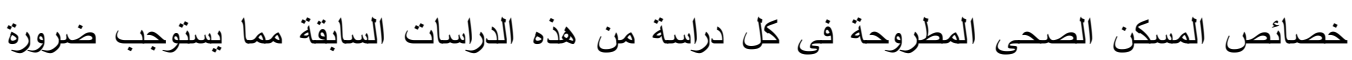

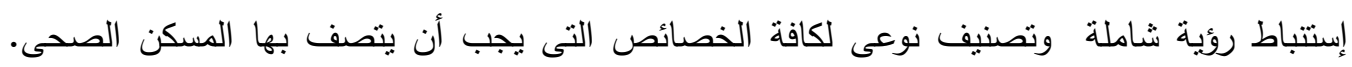

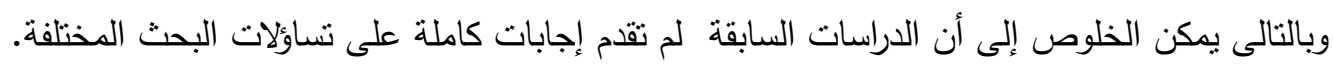

يهدف هذا البحث بشكل رئيسى إلى إستتباط كافة الخصائص التى يجب أن تتوافر بالمسكن

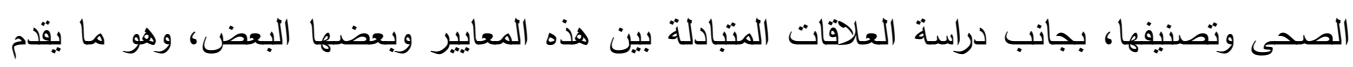

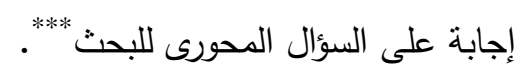

4-1 منهجية البحث:

لتحقيق هدف البحث فإن الدراسة تستخدم المنهج الوصفى التحليلى فى التعرف على الدفاهيم المختلفة

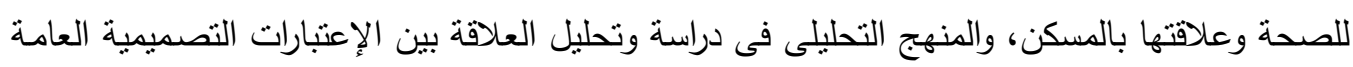

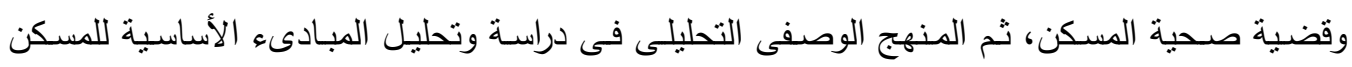

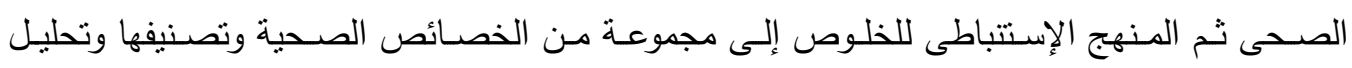
للملامح العامة للعلاقات المتبادلة فيما بينها (شكل 1).

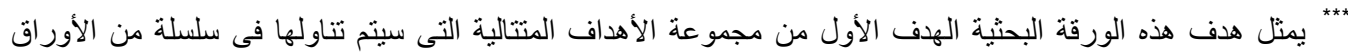

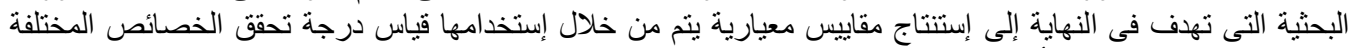

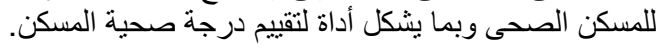




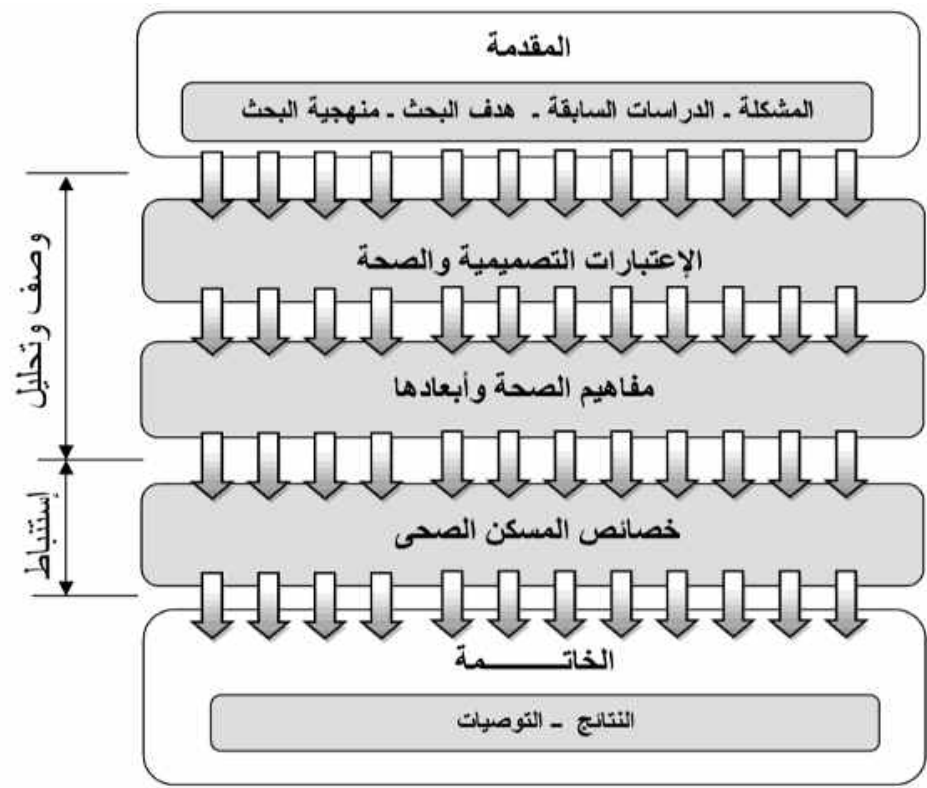

شكل1: تمثوات وهيكل الدراسة

2- الإعتبارات التصميمية والصحة:

تنبثق الاعتبارات التصميمية للمسكن من مضمون مفهوم العمارة والتي يعرفها "سامي" بأنها

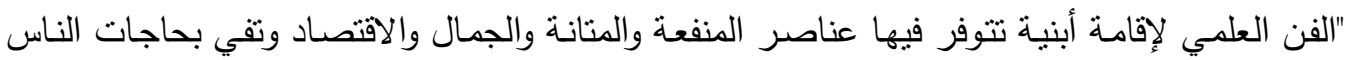

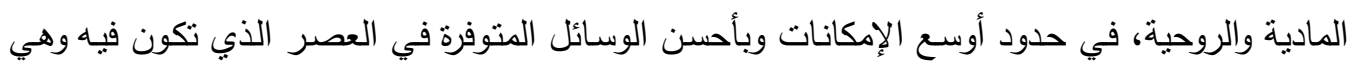
طريقة في العمل وبتفكير ومنطق سليم" وعرف فتروفيوس العمارة بثلاث محاور وهي (المنفعة، المنانة، الجمال) وهي أسس النظرية الوظيفية في العمارة التي تعتمد على التركيز على المنفعة والمتانة والجمال

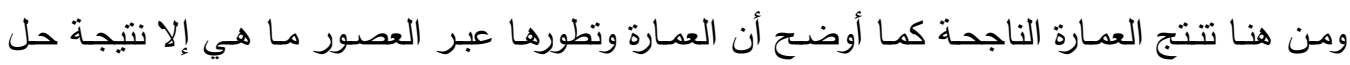

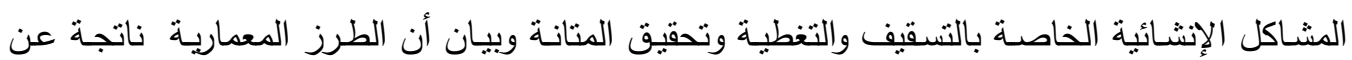
المواد وأفضل الأساليب الإنشائية التي تتوافر في كل عصر الأنة [4].

\section{1-2 1-2 الإعتبارات التصميمية:}

حدد "Merrit وأخرون" (2001) تسعة من الإعتبارات التصميمية الواجب مراعاتها عند تصميم المبنى، وهى كالتالى[16]:

يجب أن يحقق المبنى الأهداف التى حددها العميل.

يجب أن يكون التصميم قابلاً للتتفيذ بالتقنيات المعروفة والأدوات المتاحة وفى الوقت التهن المناسب.

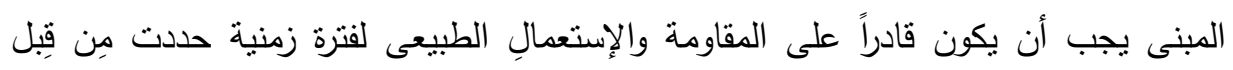


يجب أن يكون داخل وخارج المبنى ساراً بصرياً.

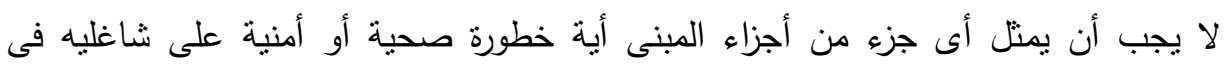

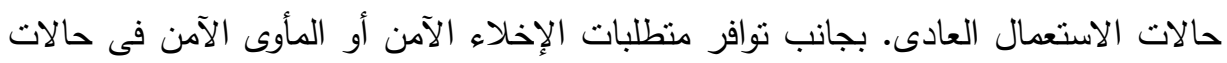
الطوارى.

يجب أن يوفر المبنى درجة حماية من العناصر المختلفة، وأن يوفر تحكم فى كل من الهواء

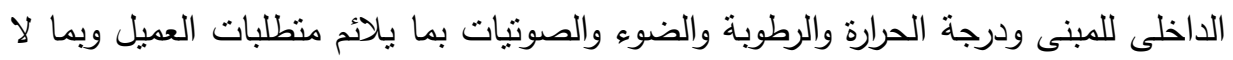

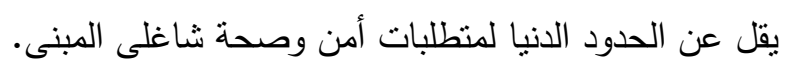
يجب أن يقلل المبنى الثأثيرات العكسية على البيئة.

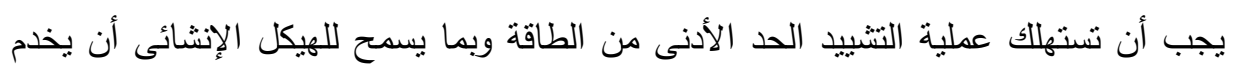
أهدافه. يجب أن تكون تكاليف الإنشاء والصيانة والإصلاح والتعديلات المستقبلية المتوقعة ضمن الحدود النى حددها العميل. وبقراءة لهذه الإعتبارات نجد أنها تضمنت تسعة من الإعتبارات التى يجب أن تراعى عند

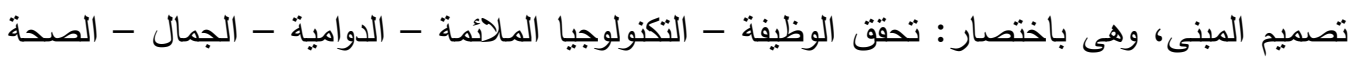
والأمان - التحكم البيئى الداخلى - أقل نأثير بيئى خارجى - أقل طاقة إنثاء - الاقتصاد.

العلاقات المتبادلة بين الإعتبارات التصميمية والصحة: 2-2

ترتبط الإعتبارات التصميمية فيما بينها بالعديد من العلاقات المتبادلة، إذ تؤثر وتتأثر هذه

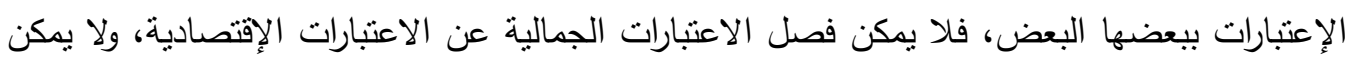

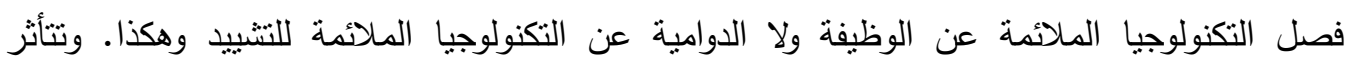

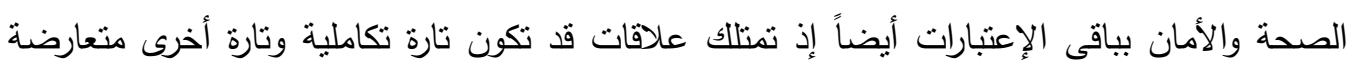

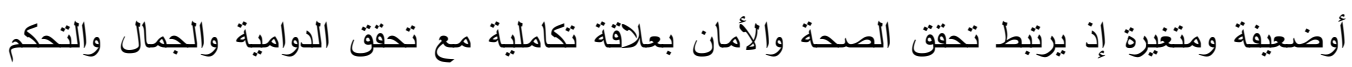

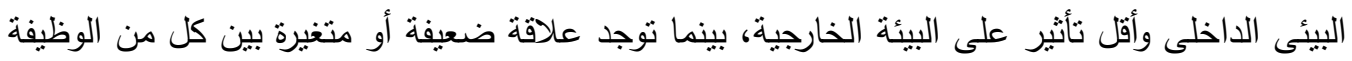

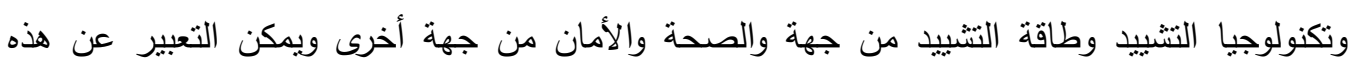




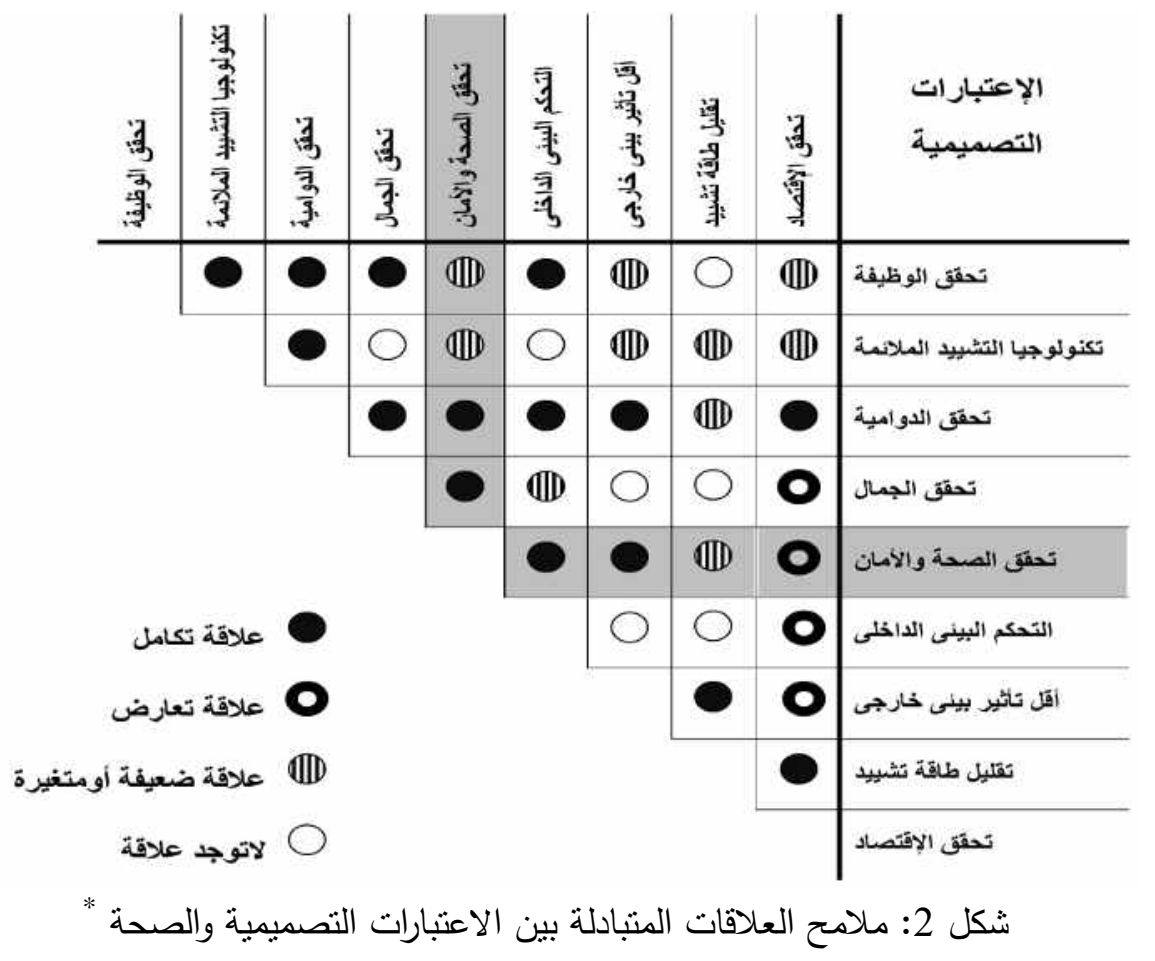

3- مفهوم الصحة وأبعادها:

يمثل التعربف الصادر عن منظمة الصحة العالمية أشثر التعريفات التى تتاولت مفهوم الصحة، بينما قدم القاموس الطبى ثثلاثة تعريفات للصحة. • • تعريف منظمة الصحة العالمية:

يعتبر التعريف الصادر عن منظمة الصحة العالمية، والذى صدر فى 1948 ولم يعدل منذ ذلك

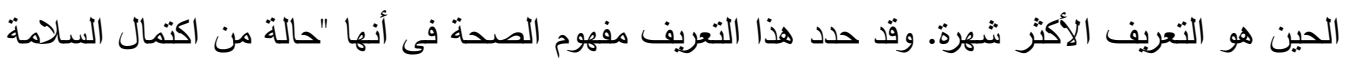

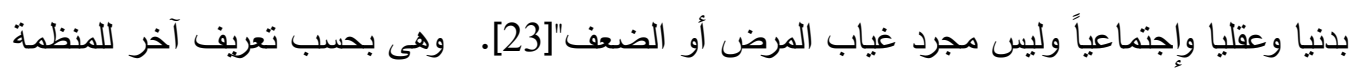
هى "حالة التكامل العضوي والعقلي والنفسي للانسان"[8] 


\section{تعريف القاموس الطبى:}

حدد القاموس الطبى ثلاثة تعريفات لكلمة "الصحة /Health" كما يلى [22]:

- - الصحة هى حالة الجسم العادية، أي حالة الثعور بالصحة وغياب المرض الجسمي أو العقلي، بحيث تؤدي جميع أعضاء الجسم وظيفتها العادية. - - هى حالة التوازن الديناميكى التى تعطى القدرة للأفراد على مواجهة الظروف المعيشية على الوجه

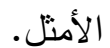

- - هى حالة تتسم بالتكامل التشريحى والنفسى والعضوى، والقدرة على إحترام الأسرة والعمل وأعراف

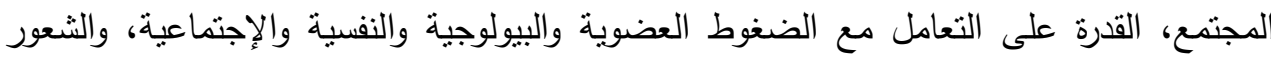

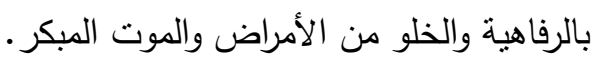
وفى ضوء التعريفات السابقة، فإنه يمكن الخلوص إلى أن مفهوم الصحة هو سلامة وخلو

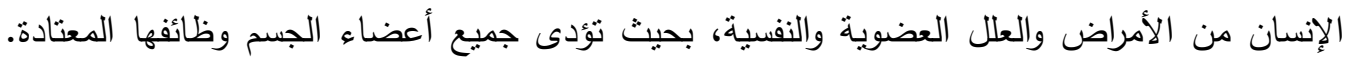

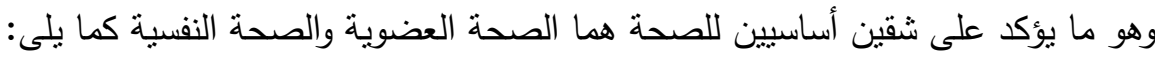
• الصحة العضوية: تعني خلو الجسم من الأمراض والآلام والقدرة علي ممارسة جميع الأنشطة بالقوة

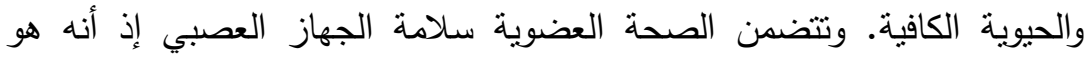

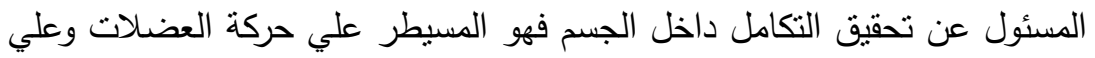
الدورة الدموية كما تتضمن سلامة الجهاز الغدي إذ أنه المسئول عن تحقيق التوازن الكيميائي داخل الجسم [5]. وتتطلب الصحة العضوية خلو البيئة المحيطة من الملوثات بما لا يؤثز علي قدرة الإنسان علي الإنتاج اقتصادياً واجنماعياً. • الصحة النفسية: هى الثرط أو مجموعة الثروط الواجب توافرها حتى ينم التكيف بين المرء ونفسه،

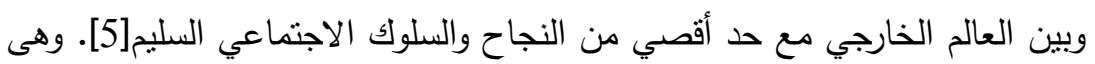

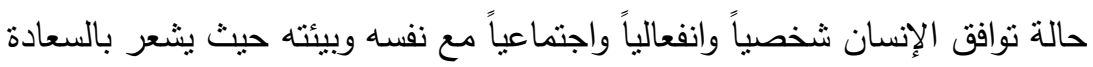

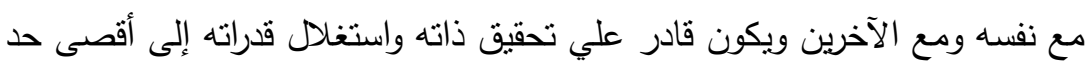
ويكون قادراً علي مواجهة مطالب الحياة ومتغيراتها[3] ".

4- - 5 - 5هوم وخصائص المسكن الصحى:

* ظهر الاهتمام بدراسة تأثير البيئة علي سلوك الإنسان في إطار علم النفس التجريبي في المجتمعات الأمريكية و الغربية في الربع الأخير من القرن التناسع عشر وبلغة المدرسة الوظيفية يعتبر السلوك هو "التكيف الحادث بين الكائن وبيئته". 
فى محاولة الوصول إلى خصائص محددة للمسكن الصحى، فإنه يجب أولاً الوقوف على

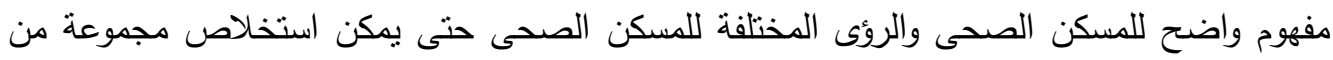
الخصائص التى يجب أن تتحقق فى المسكن حتى يصبح صحياً.

4-1-4 مفهوم المسكن الصحى:

يسهم المسكن فى تحقيق حياة صحية لمستخدميه إذا ما أحسن تصميمه وأُخذ فى الإعتبار بعض الإعتبارات التى تقود لتجنب التأثيرات السلبية للمؤثرات المختلفة على صحة فألى فاطني المسكن.

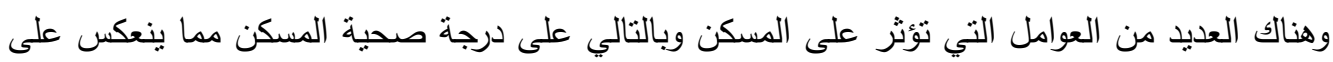

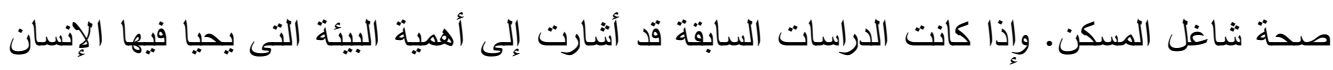
وتأثيراتها على صحته، فإنه من الطبيعى أن يكون للبيئة المبنية النى يحيا فيها الإنسان ويمارس فئها

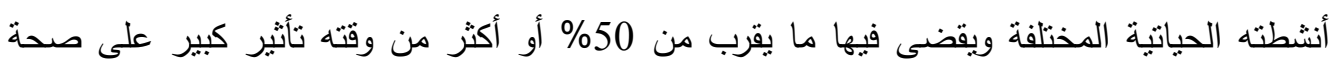

$$
\text { وجسم الإنسان[9]. }
$$

وقد عرفت منظمة الصحة العالمية المسكن الصحي بأنه المسكن الذي يكون مريحاً يبعث على الإنى البهجة والتفاؤل ويوفر للإنسان احتياجاته من الخصوصية ويمكنه من ممارسة جميع أنشطته ويساعده

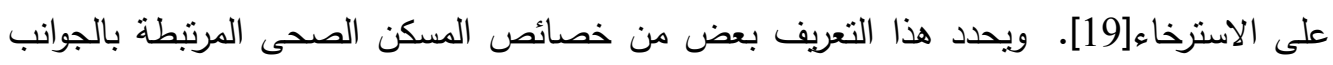
النفسية فى إغفال لبعض الخصائص الأخرى ذات الإرتباط بالصحة العضوية لقاطنى المسكن. ويرى الباحثون، وبناء على التعريفات السابقة للصحة بشقيها العضوى والنفسى، وتعريف

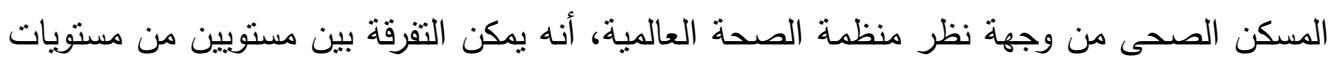

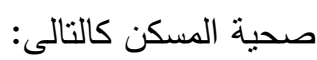
المسكن الصحى السلبى: هو الذى لا تتسبب عناصره ومكوناته فى أية تأثيرات سلبية على صحة المستخدم. • المسكن الصحى الإيجابى: هو الذى لعناصره ومكوناته تأثثرات إيجابية على صحة مستخدميه وتحسن صحة مستخدميه العضوية والنفسية. وبالتالى يمكن بلورة مفهوم وتعريف شامل للمسكن الصحى كما يلى: المسكن الصحى هو المسكن الأى لعناصره ومكوناته تأثيرات إيجابية على صحة

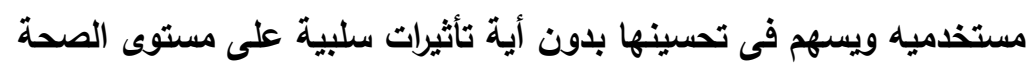
العضوية والنفسية للمستخدم. 


\section{4-2 الرؤى المختلفة للمسكن الصحى:}

تتاولت العديد من الدراسات المسكن الصحى، بجانب العديد من الهيئات الدولية المتخصصة

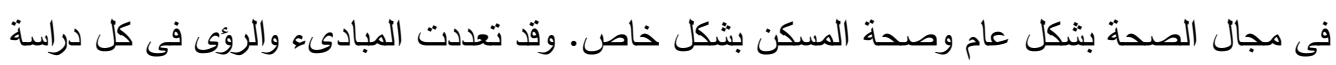
وبما يعطى نقاطاً للإتفاق ونقاطاً أخرى للإختلاف. وفى محال محاولة الباحثين الوقوف على كافة خصائص

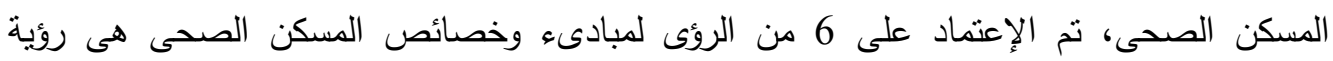

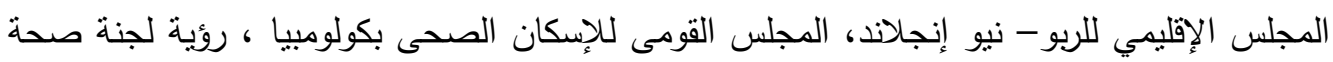

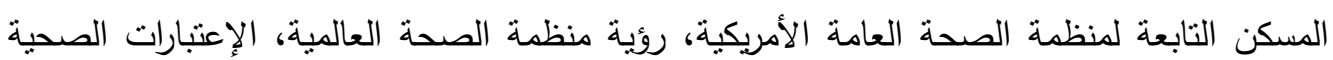

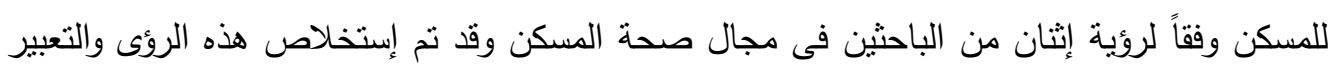
عنها كما بالجدول رقم 1.

جدول 1: مقارنة بين الرؤى المختلفة لخصائص المسكن الصحى.

\begin{tabular}{|c|c|c|c|c|c|}
\hline \multicolumn{6}{|c|}{ الخصائص الصحية للمسكن } \\
\hline $\begin{array}{c}\text { وفقاً لروئية } \\
\text { [18ower }\end{array}$ & للمسكن وفقاً لروئية & منظمة الصحة التعريف & 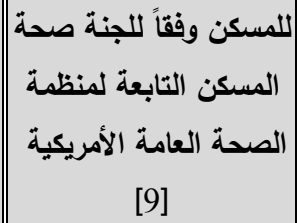 & القوفى للإسكان اللجسل & ن الإقليمي للايو - للمجلس \\
\hline الإلابلية للنظافة & الجفاف & للإحتباجات & الإحتياجات العضوية & الجفاف & الجفاف \\
\hline القابلية للتفكيك & النظافة & البهجة والتفاؤل على & الإحتياجات النفسية & النظافة & النظافة \\
\hline \multirow[t]{5}{*}{ التهوية } & التهوية الجيدة & للخصوصية & الحماية من المرض & التهوية & التهوية الجيدة \\
\hline & الخلو من الأدخنة & الإسترخاء مساعد على & الحماية من الإصابة & الأمان & الخلو من الأدخنة \\
\hline & الكيميائية السامة الخواد & \multirow[t]{3}{*}{ الراحة } & والصدمات الكهربائية من الحريق & الخلو من الملوثات & الكيميائية السامة المواد \\
\hline & الخلو من الحيوانات & & \multirow[t]{2}{*}{ الحماية من الغازات } & 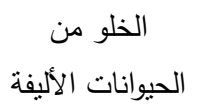 & الحيوانات الأليفة \\
\hline & الراحة & & & الحفاظ & الراحة \\
\hline
\end{tabular}

ويقدم الجدول 2 المبادىء الفرعية المنبثقة من بعض المبادىء الأساسية للمسكن الصحى وفقاً للجنة صحة المسكن التابعة لمنظمة الصحة العامة الأمريكية [15]. 
جدول 2: مبادى المسكن الصحى وفقاً للجنة صحة المسكن - منظمة الصحة العامة الأمريكية[9]*:

\begin{tabular}{|c|c|c|}
\hline ما يجب تحققه بالمسكن & \multicolumn{2}{|l|}{ الإحتياج } \\
\hline 1. الوقاية من العوامل الطبيعية. & 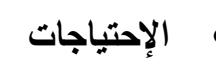 & $\bullet$ \\
\hline 2. البيئة الحرارية التى تتجنب فقدان الحرارة. & العضوية & \\
\hline 3. البيئة الحرارية التى تسمح بفقدان قدر مناسب من حرارة الجسم & & \\
\hline 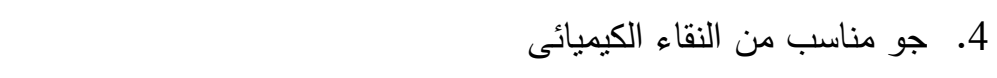 & & \\
\hline 5. اضاءة نهارية كافية وتجنب للإبهار الضوئى. & & \\
\hline 6. ضوء الثمس المباشر . & & \\
\hline 7. اضاءة صناعية مناسبة مع تجنب للإبهار الضوئى. & & \\
\hline 8. الحماية من الضوضاء الثديدة. & & \\
\hline 9. توافر المساحة المناسبة لممارسة الرياضة واللعب للأطفال. & & \\
\hline 1. الخصوصية الكافية للفرد. & الإحتياجات & $\bullet$ \\
\hline 2. الفرصة لحياة أسرية طبيعية. & النفسية & \\
\hline 3. الفرصة لإقامة حياة إجنماعية طبيعية. & & \\
\hline 4. التسهيلات التى تمكن من أداء المهام المنزلية بدون جهـ أو عناء مادى & & \\
\hline أو ذهنى. & & \\
\hline 5. تسهيلات الصيانة ونظافة الدسكن والساكن. & & \\
\hline 6. الرضاء الجمالى عن المسكن وعن البيئة المحيطة. & & \\
\hline 7. التوافق مع المعايير الاجتماعية السائدة فى المجتمع المحلي. & & \\
\hline 1. توفير مصدر مياه صحى آمن. & 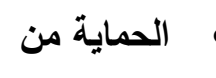 & $\bullet$ \\
\hline 2. حماية نظم إمداد المياه من التلوث. & 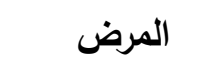 & \\
\hline 3. توافر المراحيض التى تقلل من إنتقال الأمراض. & & \\
\hline 4. الحماية من مياه الصرف الصحى وتلوث الأسطح الداخلية للمسكن. & & \\
\hline 5.تجنب وجود ظروف غبر صحية بالقرب من المسكن. & & \\
\hline 6. خلو المسكن من الحشرات. . & & \\
\hline 7. وجود تجهيزات الحفاظ على المأكولات. & & \\
\hline 8. إناحة حجم الفراغ المناسب في غرف النوم لتقليل من خطر عدوى & & \\
\hline
\end{tabular}


د. خالد صلاح سعبد ، أ.ــ. عبد الدنطلب محد على، م. عبير ياسبن مصطفى

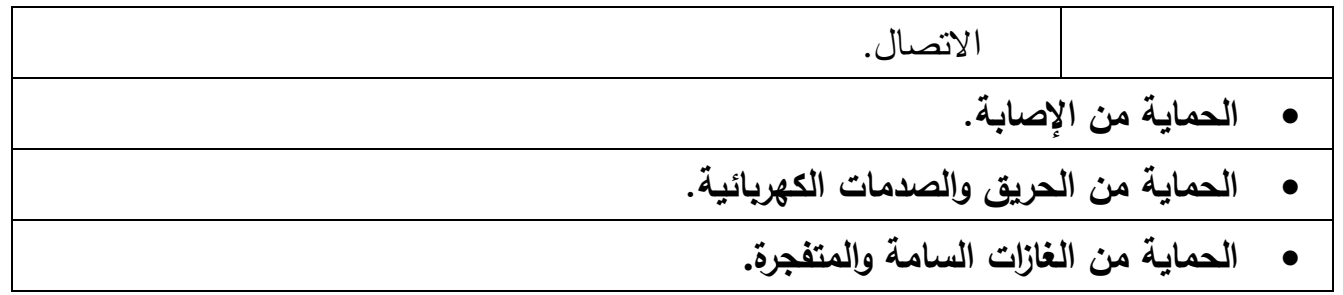

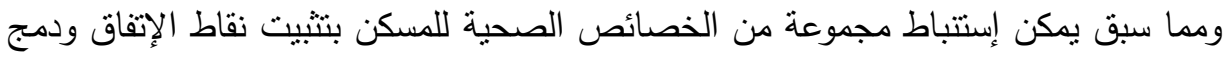

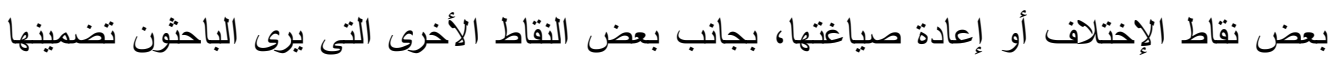
كخصائص صحية للمسكن.

\section{4-4 - 3-3 خصائص المسكن الصحى:}

بناء على الدراسات التى تم الإستشهاد بها ومثنيلاتها، وبناء على التعريف الذى خلص إليه

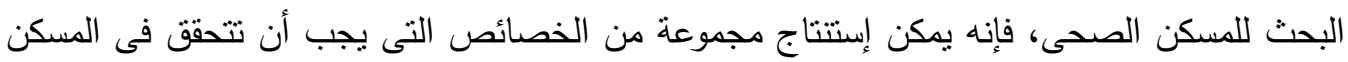

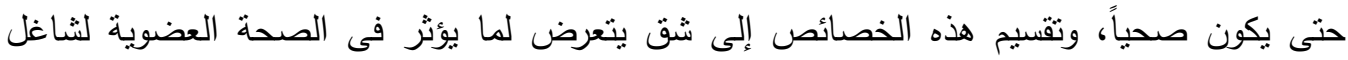

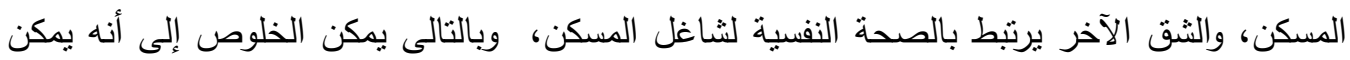
تصنيف خصائص المسكن الصحى فى مجموعتين رئيسيتين هما:

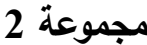

الخصائص المرتبطة بتحقيق المسكن للصحة النفية للمستخدم

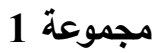

الخصائص المرتبطة بتحقيق المسكن للصحة العضوية للمستخدم

وهذه الخصائص الصحية الأساسية تتحقق من خلال مجموعات المعايير الثانوية الجزئية المختلفة

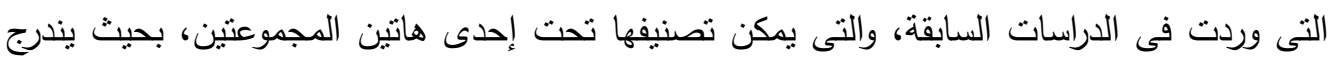

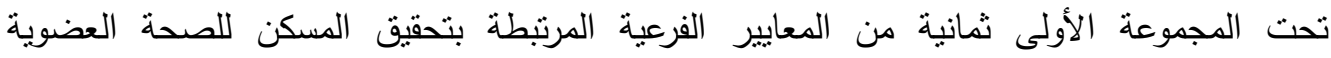
لمستخدميه، كما يندرج تحت المجموعة الثانية أيضاً ثمانية من المعايير الفرعية المرتبطة بتحقيق لهني المسكن للصحة النفسية لمستخدميه. 1-3-4 تحقق الصحة العضوية للمستخلم:

بناء على تعريف الصحة العضوية، فإنه يكمن تحقق الصحة العضوية لمشاغلى المسكن فى بـ تجنب كل ما يؤثر سلباً على جهازه العصبى، بجانب كل ما يؤثر على قدراته العضلية والعقلية، وقبل

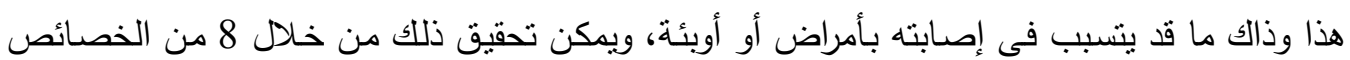


• أن يكون المسكن محققاً للراحة البصرية.

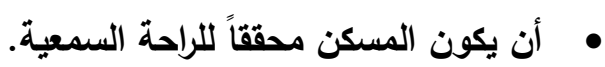

أن أنتع المسكن بالتشميس.

• أن يكون المسكن جيد التهن بائمينة.

• أن يكون المسكن جافاً.

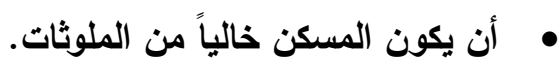

• • • أن يكون المسكن خالياً من المجالات الكهرومغناطيسية.

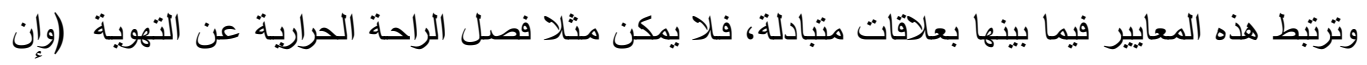

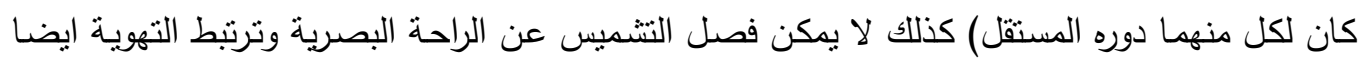

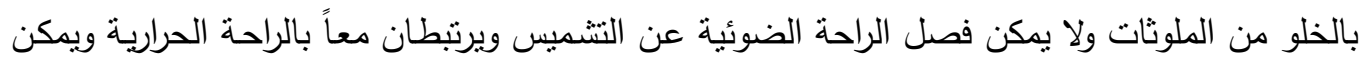
التعبير عن العلاقات التبادلية بين معايير المسكن الصحي من الناحية العضوية كما في شكل(3).

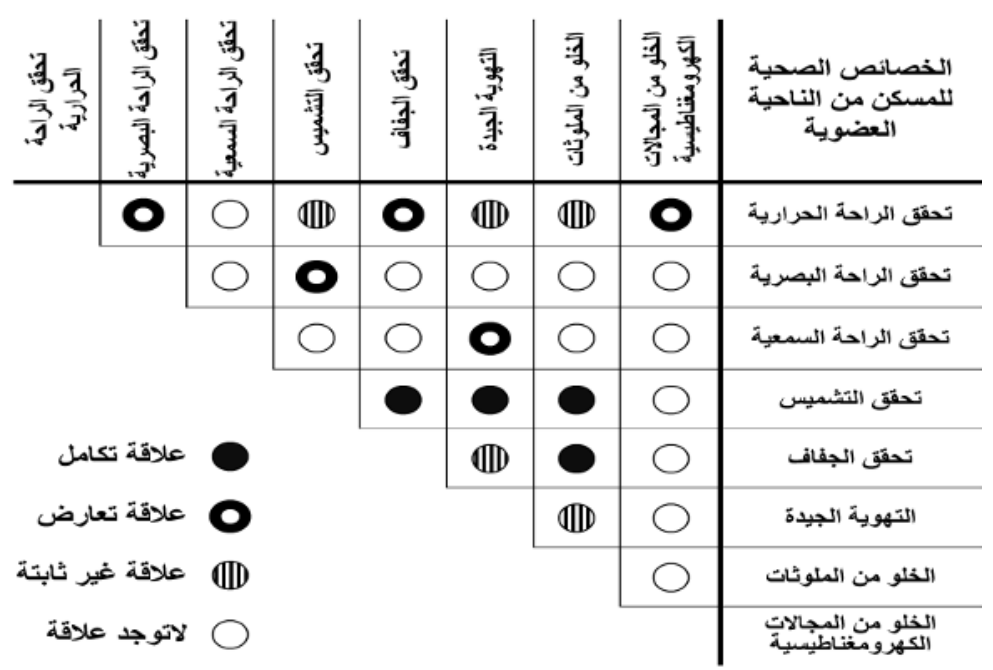

شكل 3: العلاقات المتبادلة بين خصائص المسكن الصحي من الناحية العضوية (الباحثين).

2-3-4 تحقق الصحة النفسية للمستخدم:

من التعريف السابق ذكره فى 2، ومن تعريف منظمة الصحة العالمية، فإنه يمكن التأكيد على

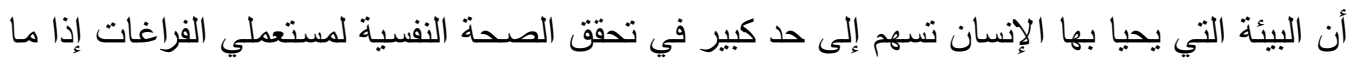

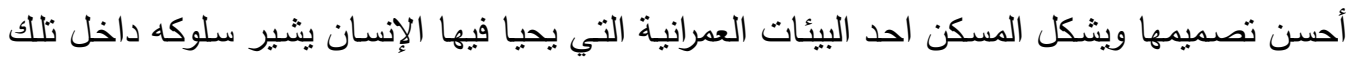
البيئة إلى التكيف القائم بينه وبين الفراغ السكني الذي يعيش فيه لذا فان تحقق الصحة النفسية للمستخدم يأتي من خلال نوافق الفرد مع البيئة المحيطة بالإضافة إلى المرونة وقدرة الفرد علي تقبل واقعة وحدود 


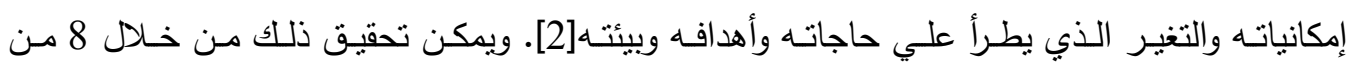
الخصائص الفرعية كما يلى:

• أن يكون المسكن محققاً للرضاء الجمالى.

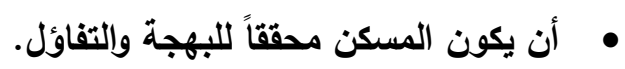

• • • • • أن يكون المسكن محققاً للامان والطمانينة.

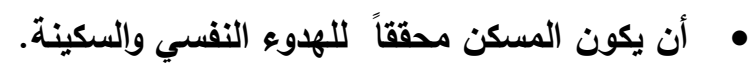
• أن يكون المبنى محققاً للخصوصية.

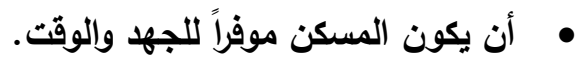
• أن يكون المسكن محققاً للإحتياجات الوظيفية (الإنتفاعية).

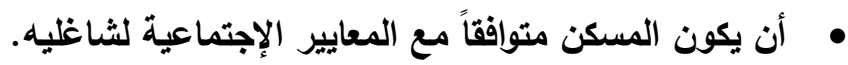

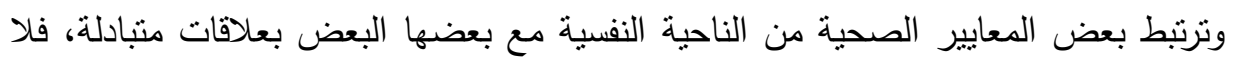
يمكن فصل البهجة والتفاؤل عن الرضاء الجمالى، ولا يمكن فصل الأمان والطمأنينة عن الهدوء والسكينة ولا الخصوصية عن الوظيفية.هذا بجانب تعارض بعض المعايير مع بعضها البعض مثل الهدوء

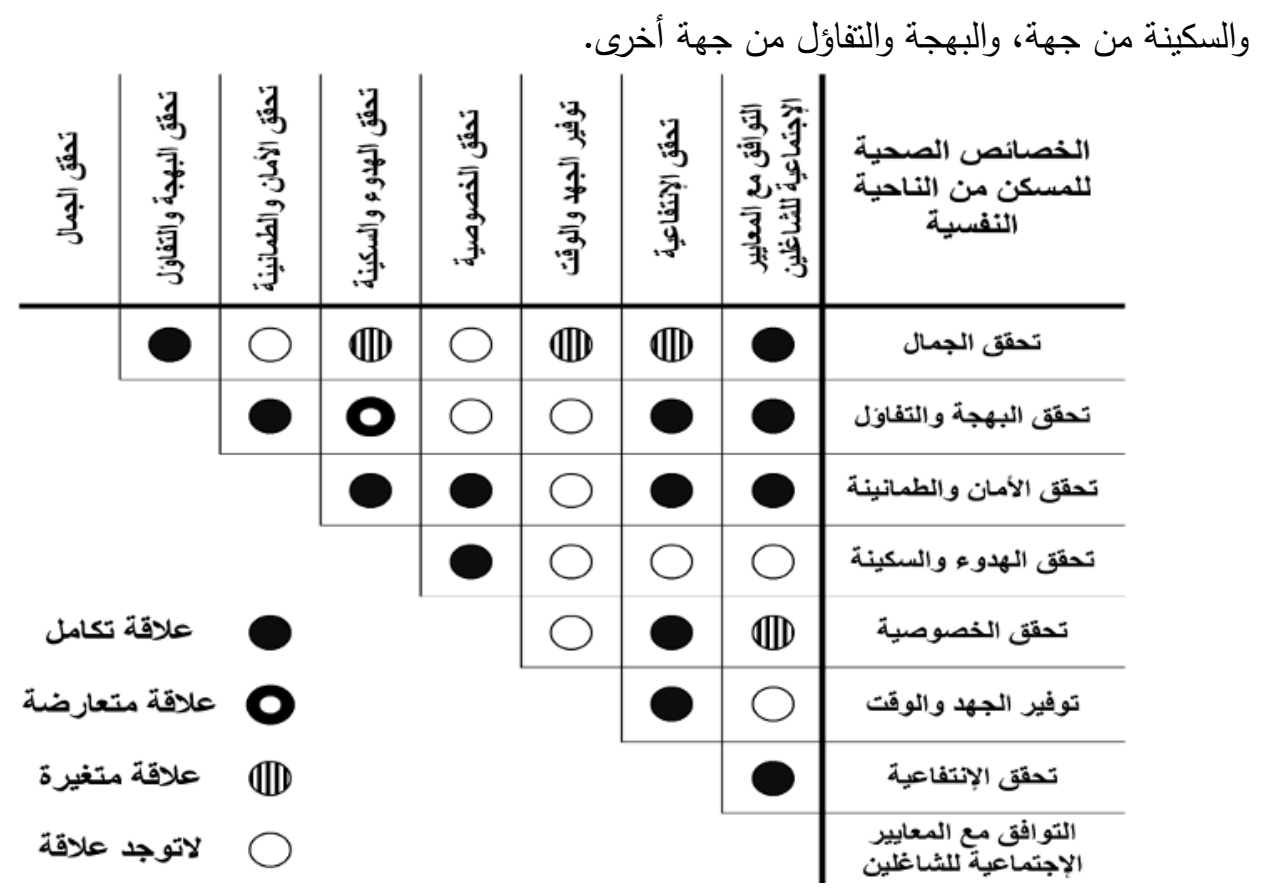

شكل 4: العلاقات المتبادلة بين المعايير الصحية للمسكن من الناحية النفسية (الباحثين). 


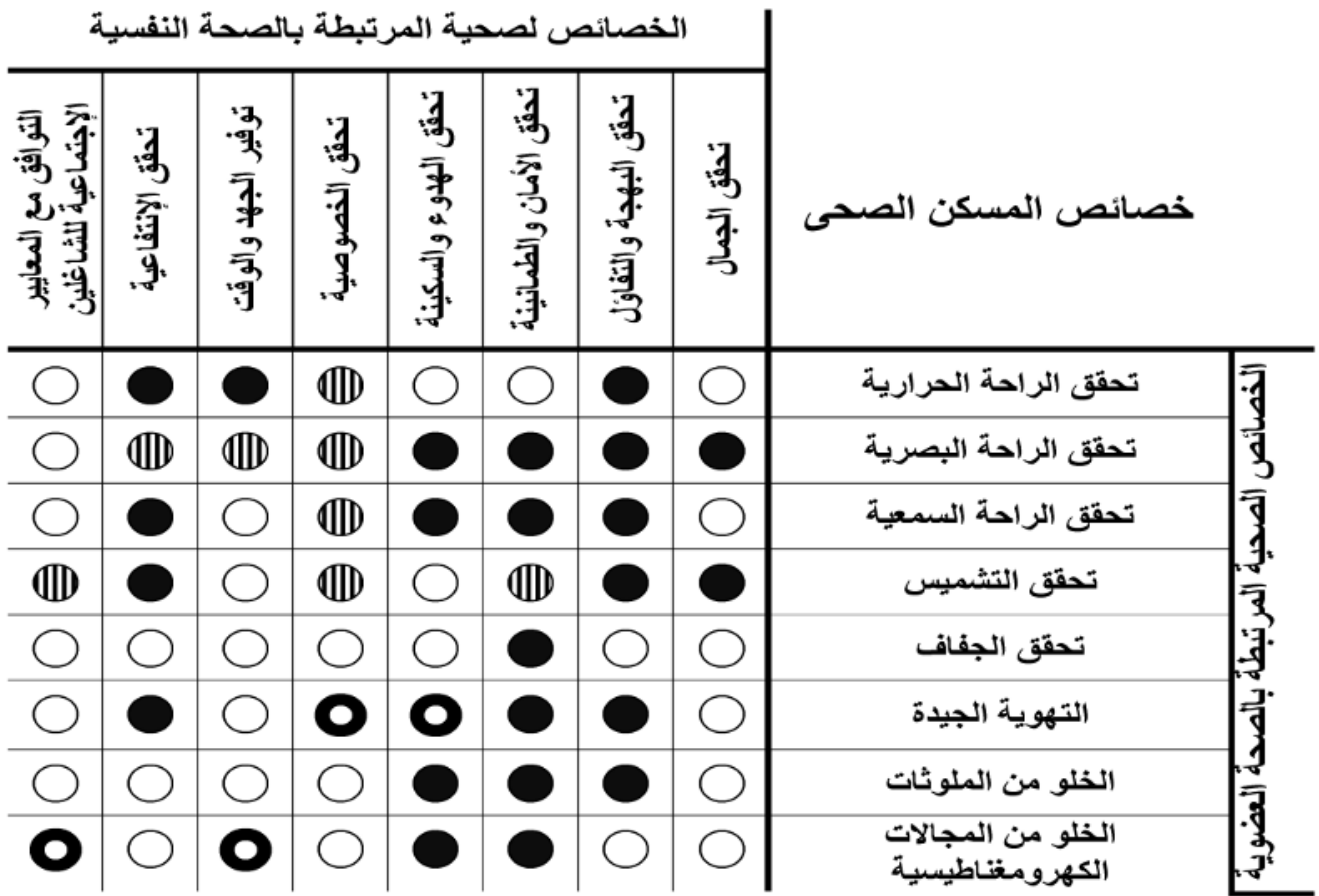

شكل 5: العلاقات المنبادلة بين المعايير العضوية والنفسية للمسكن الصحى (الباحثني)

4-4 العلاقات المتبادلة بين المعايير الصحية العضوية وإلنفية للمسكن:

بجانب ارتباط كل قسم من أقسام المعايير الصحية للمسكن بعلاقات بينية بين المعايير المندرجة أسفله (شكل 3 وشكل 4)، ترتبط المعايير الصحية العضوية والنفسية للمسكن بعلاقات متبادلة فيما بينها، فلا يمكن مثلاً فصل التأثير العضوى لتحقق معيار الراحة البصرية عن تحقق معيار البهجة والتفاؤل، أو بعض جوانب التعارض بين تحقق الراحة السمعية والخصوصية أو الراحة الحرارية

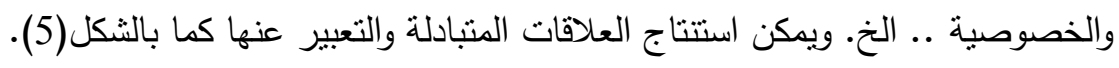
5

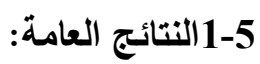
يمكن إجمال نتائج البحث فى النقاط التالية: • تمثل الصحة والأمان أحد الإعتبارات التصميمية الأساسية فى عملية التصميم المعمارى للمبانى بشكل عام وللمسكن بشكل خاص. • تتقسم الصحة إلى قسمين أساسيين هما الصحة العضوية والصحة النفسية. 
تتقسم الخصائص الصحية للمسكن إلى 8 خصائص مرتبطة بالصحة العضوية و 8

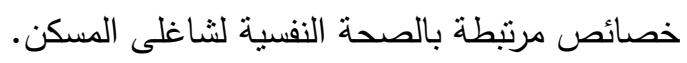

الخصائص الصحية العضوية للمسكن هى أن يكون محققاً للراحه الحرارية والبصرية

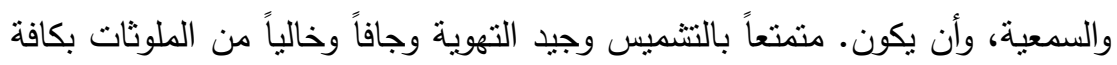
أثكالها وخالياً من المجالات الكهرومغناطيسية.

الخصائص الصحية النفسية للمسكن هى أن يكون المسكن محققاً للجمال والبهجة

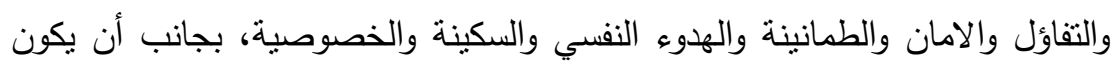

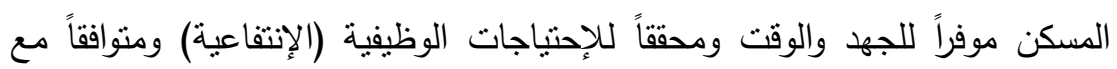
المعايير الإجنماعية لشاغليه

ترتبط خصائص المسكن الصحى مع بعضها البعض بأثكال مختلفة من العلاقات

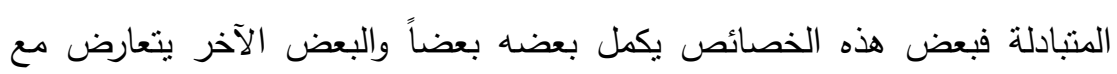
بعضه البعض. كما توجد مجموعة من الخصائص ذات العلاقة المتغيرة والتى تارة

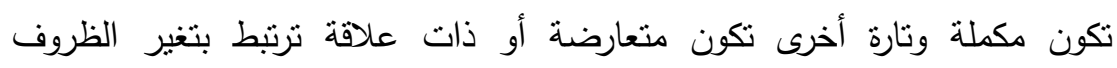
المحيطة فتحولها من متعارضة لمكملة.

ويناءاً عليه يمكن القول أن الدراسة قد حققت الههف المحدد لها بإستخلاص وتصنيف مجموعتان من الخصائص الصحية للمسكن.

2-5 مناقشة:

إذا كانت الدراسة قد أظهرت أن بعض الخصائص قد يتعارض تحقيقها مع تحقق خصائص

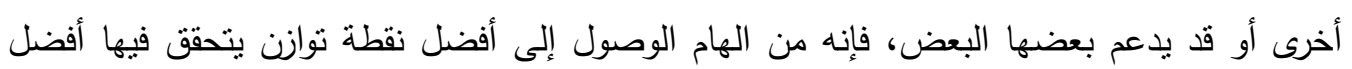

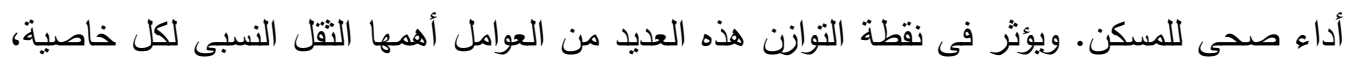

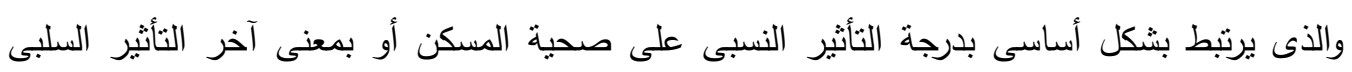

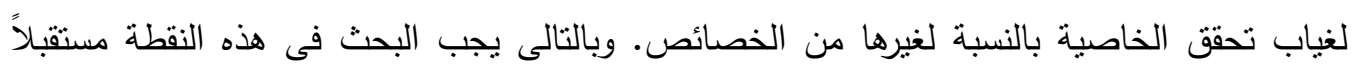

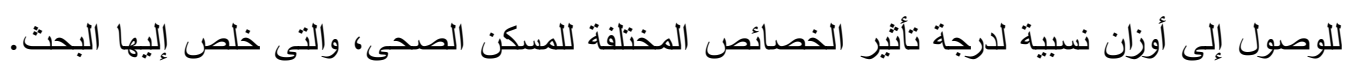

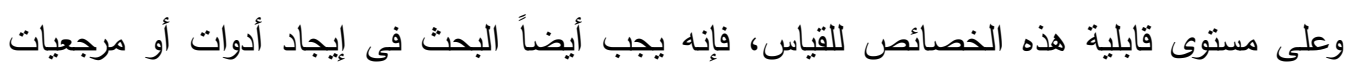
لقياس درجة تحقق الخصائص المختلفة فى المسكن وخاصة المرتبطة بالصحة النفسية للمستخدم سواء فى مرحلة التصميم أو للمبانى القائمة. 
بناء على ما جرى من دراسات فى هذه الورقة البحنية، فإنه يمكن الخلوص لمجموعة من التوصيات كما يلى:

• على المعمارى عند قيامه بالتصميم المعمارى للمسكن أن يضع فى إعنباره مجموعة

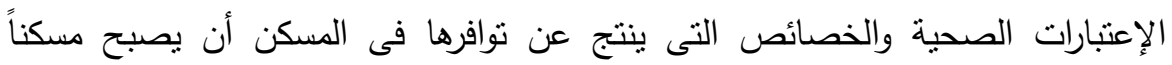
صحياً، وذلك لما للمسكن من أهية ومردود كبير على صحة قاطنيه على المستويين العضوى والنفسى.

على المستخدم - بمساعدة متخصصين- التأكد من تحقق الخصائص الصحية للمسكن

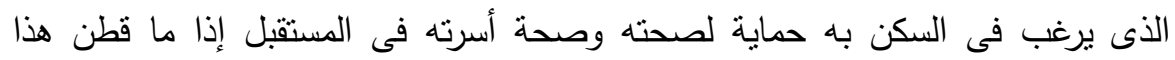
المسكن.

يجب زيادة الوعى العام لاى المواطن بأهمية السكن فى مسكن صحى والتوعية بالأساليب والمعالجات التى يمكن أن نرفع من درجة صحية المسكن القائم.

على المؤسسات التعليمية المعمارية تضمين خصائص المسكن الصحى فى مقررات النظريات والمقررات المرتبطة بالتصميم المعمارى.

على المراكز البحثية والباحثين مثابعة البحث فى النقاط المفتوحة للدراسة مثل إيجاد أوزان

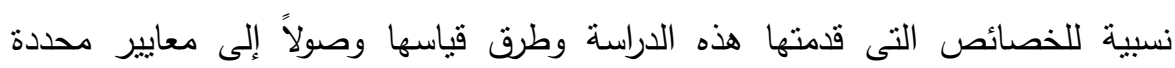

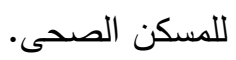

\section{المراجــع}

1 الطيب،نوري وجرار بشير (2004):"التلوث الداخلي للمساكن"، مدينة الملك عبد العزيز للعلوم والتقنية، المملكة العربية السعودية. 2 القوصي، عبد العزيز (1975): "أسس الصحة النفسية"، دار النهضة العربية، القاهرة. 3 زهران، حامد عبد السلام (1977): "الصحة النفسية والعلاج النفسي" الطبعة الثانية ،عالم الكتب القاهرة. 4 سامي، عرفان (1967): "النظرية الوظيفية في العمارة" ، الطبعة الثانية ، دار المعارف ،القاهرة 
5 عسكر، علي و الأنصاري، محد (2004) "البعد النفسي للعلاقة بين البيئة والسلوك، دار الكتب

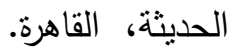

6 علي، صبره محمد وشريت، محمد عبد الغني (2004): "الصحة النفسية والتوافق النفسي، دار المعرفة الجامعية ، الإسكندرية.

7 American Lung Association (1999): "Indoor Air Pollution, An Introduction For Health Professional.

8 Bok , Sissela (2004) Rethinking the WHO Definition of Health," Working Paper, Harvard Center for Population and Development Studies, Vol. 14, No. 7 (October 2004).

9 Centers for Disease Control and Prevention and U.S. Department of Housing and Urban Development. (2006) "Healthy Housing Reference Manual". Atlanta: US Department of Health and Human Services, USA.

10 http://www.medilexicon.com/medicaldictionary.php?t=39448

11 Indoor Air Pollution: An Introduction for Health Professionals"(2009) Cited in http//www.epa.gov/iaq/pubsl (April 2009).

12 Interpretation for standard 62-2001" (2001) (Ref section 6.2 Indoor Air Quality) Cited in: http://www.ashrae.org/ technology (06-04-2001).

13 J Lang, Dowden \& Ross (1974) "Designing for Human Behavior :Architecture and the Behavioral Science" Cited in: http://wallace.tosm.ttu.edu/ETD-db(30-52008).

14 Janie L. Harris, M.Ed., CRS (2006) "Seven Steps to a Healthy Home" AgriLife Extension Service, Texas A\&M System. January 2006, (http://fcs.tamu.edu/housing/healthy_homes/sevensteps.php)

15 Mermin, Naomi, Morle, Rebecca L., Powel, Kevin, Tohn, Ellen (2006) "Comparing Green Building Guidelines and Healthy Homes Principles:A Preliminary Investigation" The National Center for Healthy Housing, Colombia

16 Merritt, Frederick S. and Ricketts, Jonathan T. (2001) "BUILDING DESIG AND CONSTRUCTION HANDBOOK" Sixth Edition, McGRAW-HILL, New York

17 World Health Organization "http://www.who.int"

18 Power, John (1994) "Improved Indoor Air Quality in an Energy Efficient Demonstration House" Energy Efficient Building Association Excellence in Housing Conference - Dallas Texas, February 1994

19 Ray Ranson (1991)" Healthy Housing" :Practical Guide, World Health Organization. Regional Office for Europe, Published by Taylor \& Francis.

20 The National Center for Healthy Housing, Colombia http://www.nchh.org/WhatWe-Do/Healthy-Homes-Principles.aspx

21 Tohn, Ellen (2006) "Building Guidance for Healthy Homes", Asthma Regional Council of New England, The Medical Foundation, Dorchester, MA

22 Webster's NEW World: Medical Dictionary (2008) third edition, Wiley Publishing, inc., Hoboken, New Jersey.

23 World Health Organization "http://www.who.int" 